\title{
BARRED-BEACH MORPHOLOGICAL CONTROL ON INFRAGRAVITY MOTION
}

\author{
Rafael Almar ${ }^{1,5}$, Rodrigo Cienfuegos ${ }^{1}$, Eduardo Gonzalez ${ }^{1}$, Patricio Catalán ${ }^{2}$, Hervé \\ Michallet $^{3}$, Philippe Bonneton ${ }^{4}$, Bruno Castelle ${ }^{4}$ and Leandro Suarez ${ }^{1,3}$
}

\begin{abstract}
A conceptual analysis of the coupling between bars and infragravity waves is performed combining laboratory experiments and numerical modeling. Experiments are carried out in a wave flume with a barred profile. The Boussinesq fully-nonlinear model SERR1D is validated with the laboratory data and a sensitivity analysis is performed next to study the influence on the infragravity wave dynamics of bar amplitude and location, and swash zone slope. A novel technique of incident and reflected motions separation that conserves temporal characteristics is applied. We observe that changing bar characteristics induces substantial variations in trapped energy. Interestingly, a modification of swash zone slope has a large influence on the reflected component, controlling amplitude and phase time-lag, and consequently on the resonant pattern. Variations of trapped infragravity energy induced by changes of swash zone slope reach $25 \%$. These changes in infragravity pattern consequently affect short-wave dynamics by modifying the breakpoint location and the breaking intensity. Our conceptual investigation suggests the existence of a morphological feedback through the action of evolving morphology on infragravity structures which modulates the action of short-waves on the morphology itself.
\end{abstract}

Keywords: Longwave dynamics, Sandbar, Swash, Nearshore, Laboratory experiment, Non-linear Boussinesq wave modeling, Radon transform, Incoming/Outgoing wave separation, Infragravity resonance

\section{INTRODUCTION}

Nearshore sandbars are ubiquitous alongshore wave-exposed natural beaches (Winjberg and Kroon, 2002). Their presence affects the hydrodynamics, for instance, driving wind-induced surfacegravity waves to break, a process that can be associated to energy dissipation and transfer to the infragravity frequency band. Infragravity may be predominant close to the shoreline due to short-waves saturation and this has been observed to be even enhanced by the presence of a submerged bar which limits short-wave amplitude (Ruessink, 1998; Senechal et al., 2002). The close correspondence between the length scales of infragravity waves and morphological features has suggested a strong coupling (Symonds \& Bowen 1984; O'Hare \& Huntley 1994; Aagaard and Bryan, 2003). However, the interaction between nearshore sandbars and infragravity motion remains unclear. Observations indicated negligible to small effects of bound infragravity waves on morphology (e.g. Ruessink et al., 1998) though last findings suggest that infragravity may have an effect on short-wave dynamics (Michallet et al., 2007). On the contrary, it is not clear what role plays the morphology on infragravity dynamics.

Onshore propagating long waves (either free or released bound waves) may reflect at the shore and interact with incident waves, leading to resonance. Using laboratory data, Baldock et al. (2004) showed that the presence of a bar induces an infragravity wave frequency selection associated to standing trapped wave modes. A modal analysis indicated that the resonance produced by the offshore migration of the breakpoint over the bar is consistent with a seiching between the bar and the shore. However, the influence of the bar amplitude and its location on trapped energy has not been investigated extensively. Similarly, the swash zone slope may also be of importance by means of frequency selection and the time-lag it adds to the reflected wave (Baldock and Holmes, 1999). These morphological parameters, by controlling infragravity structure, are suspected to provide a strong feedback between infragravity fluid motion and the evolution of morphological features.

To date, one of the limiting factors in studying morphological-infragravity interactions was the lack of appropriate dataset and numerical models. The observations made during the ECORS2008 experiment at Truc Vert beach, in presence of a well developed subtidal bar, meso-macro tidal environment, and energetic wave conditions, revealed the presence of energy peaks in the infragravity band. But studying the role of morphology on this infragravity component is a difficult task from scarce existing measurements and uncontrolled wave conditions. In this paper, we overcome these issues by using dense measurements acquired in a wave flume in a scaled experiment in Froude similarity with the conditions encountered during the ECORS2008 experiment (Figure 1, Sénéchal et al., 2011). Two different tide levels are used in order to highlight the influence of the water depth over the bar crest on

\footnotetext{
${ }^{1}$ College of Engineering, Pontificia Univ. Catolica de Chile, Santiago, Chile

${ }_{2}$ Departamento de Obras Civiles Univ. Técnica Federico Santa María, Valparaíso, Chile

${ }^{3}$ UMR LEGI, (UJF-INPG-CNRS), Grenoble, France

${ }^{4}$ UMR EPOC (Univ. Bordeaux-CNRS), Bordeaux, France

${ }^{5}$ UMR LEGOS (IRD-CNRS-CNES-Univ. Toulouse), Toulouse, France
} 
short wave and infragravity behavior. A novel signal processing technique based on the Radon transform (Deans, 1983) is used to separate incident and reflected waves. The method is shown to capture the temporal characteristics of the signal (frequency and phases). A Boussinesq-based 1D wave model is compared to the experimental data and used to explore the influence that the bar amplitude and location, and swash zone slope has on the infragravity dynamics. We discuss on possible mechanisms for morphology feedback. By combining laboratory experiments, numerical modeling and novel signal processing techniques, we aim at providing new insights on the mechanisms of interaction between a barred-beach morphology and infragravity waves.

\section{METHODS}

\section{Experimental set-up}

Wave experiments were conducted in the laboratory wave flume of the Instituto Nacional de Hidráulica (INH) located in Peñaflor, near Santiago of Chile. The flume is $70 \mathrm{~m}$ long and has a square cross section with side length of $1.5 \mathrm{~m}$. It has concrete bottom and side walls and was prepared with an impermeable smooth concrete plane beach of $1 / 80$ slope $(x=0 \mathrm{~m}$ at the toe of the slope, positive shoreward, see Figure 1). The flume is equipped with a hydraulically driven piston-type wave paddle. Back reflection at the wave paddle is minimized by active absorption through DHI-AWACS system (Active Wave Absorption Control System). A large number of experiments were run, using a single 27-minute wave signal time series derived from a JONSWAP type spectrum with a significant wave height $\mathrm{H}_{\mathrm{mo}}=8 \mathrm{~cm}$, a peak frequency $\mathrm{f}_{\mathrm{p}}=0.41 \mathrm{~Hz}$. The still water depth at the wave maker was fixed at $\mathrm{h}_{0}=52 \mathrm{~cm}$. Measurements of the free surface displacements were performed all over its length at high spatial resolution $(0.2 \mathrm{~m}$ to $1 \mathrm{~m})$ using resistive rods. Keeping a fixed rod at a distance of $2 \mathrm{~m}$ from the wave-maker and performing redundant measurements at several other locations was considered to verify the repeatability of the experiments.

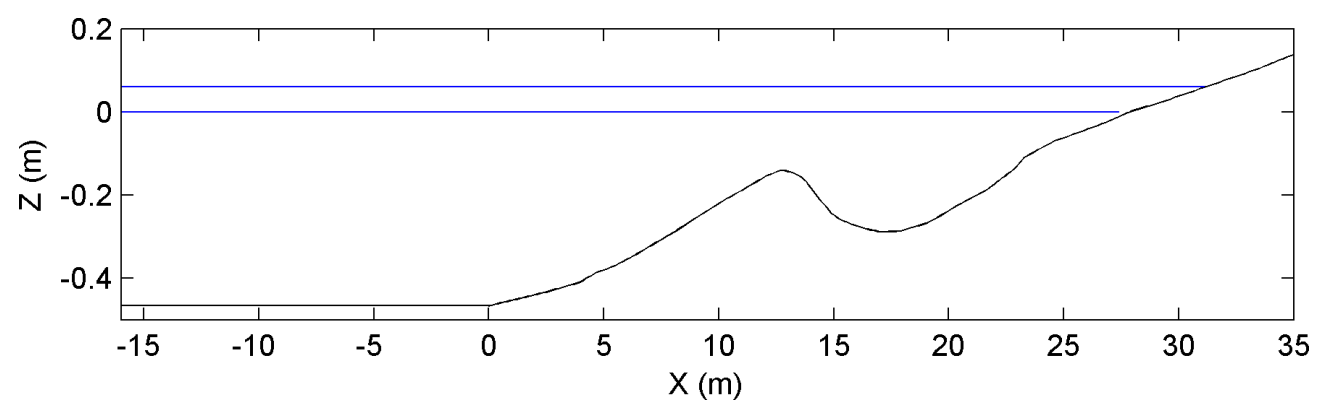

Figure 1: Sketch of the experimental wave tank at the Instituto Nacional de Hidráulica and wave gauge locations.

Free surface measurements were acquired at $20 \mathrm{~Hz}$, and a simple low-pass filter was used to separate orbital motions from turbulence in velocity time series. Two water levels were considered, one with $0.14 \mathrm{~m}$ depth over the bar and one with $0.2 \mathrm{~m}$. These two levels stand for the mid and high tide levels encountered at Truc Vert beach. The mid level is expected to induce a moderate wave-breaking over the bar whereas the high level should limit breaking producing only sporadic events over the bar.

\section{Numerical modeling}

Numerical computations are conducted using the phase resolving fully non-linear 4th-order finite volume Boussinesq model SERR1D (Cienfuegos et al., 2010a). This model includes a parameterization for the wave-breaking energy dissipation.

The model has been previously validated with laboratory data obtained at the INH wave flume for very non-linear conditions on a gently sloping beach (Cienfuegos et al., 2010b). The model showed good performances in representing both short-wave dynamic and energy transfer to infragravity band. Nevertheless, some discrepancies with data were observed in the swash zone, where the numerical model seems to underestimate the amount of reflected energy wave..

\section{Incident and reflected waves separation through Randon Transform}

Long-wave resonance analysis requires the separation of incident and reflected wave components. Usual methods (Guza et al., 1984; van Dongeren et al., 2007) rely on measurements of both surface elevation and currents to compute the energy propagating shoreward and seaward directions. The latter 
does not allow describing wave transformation and interaction with reflected in the temporal domain. A very good alternative is to use a method based on the Radon transform (Deans, 1983) which preserves the temporal characteristics of the incident and reflected wave signals. See Almar et al. (In prep.) for a complete description and validation.

The signal processing has two steps. An angular projection $(\beta, \theta)$ of a $2 \mathrm{D}$ field $(\mathrm{x}, \mathrm{y})$ is first performed by the Radon transform (Eq. 1), followed by a back-projection for selected ranges of angles (Eq. 2) :

$$
R(\varnothing, \rho)-\oiint f(x, y) \delta(x \cos \emptyset+y \sin \emptyset-\rho) d x d y
$$

$$
f(x, y)=\oiint R(\emptyset, \rho) d \emptyset d \rho
$$

Interestingly, in the case of a $2 \mathrm{D}$ field which is a wave spatio-temporal data, the Radon-estimated angles with values ranging between $\left[0^{\circ} ; 90^{\circ}\right]$ and $\left[90^{\circ} ; 180^{\circ}\right]$ can be converted into a celerity corresponding to positive and negative propagating waves, respectively.

\section{RESULTS AND DISCUSSION}

The numerical simulations are first compared with laboratory data. Next, the model is used to determine the influence of morphological parameters (bar amplitude, location and swash zone slope) on the infragravity dynamics. A low-pass filter is applied to extract infragravity waves (frequency $<3 / 5$ peak frequency) from surface elevation time series. Incident and reflected components are separated using the Radon-derived processing described in the previous section.

\section{High- and low-frequency band data-model comparison}

For model validation, we run SERR1D using the free surface time series measured $2 \mathrm{~m}$ from the wave-paddle using an absorbing-generating boundary conditions. In the Figure 2 we present measured and numerically computed significant wave height profiles along the flume for the two water levels. For the high water level case, the short-wave height peaks over the bar $(x=12 \mathrm{~m})$, but there is little dissipation by breaking over it. The model reproduces this behavior but slightly underestimates the shoaling over the bar. In the same figure, significant long-wave height is also depicted. Long-wave height steadily increases until reaching the shore where they strongly dissipate. The model results are in good agreement thus showing that the energy transfer from high to low-frequency is well reproduced. In the lower panel of Figure 2, results for the low water level case are presented. It is seen that short-wave amplitude decreases substantially over the bar, indicating breaking occurrence. For the long-wave heights, a different behavior is observed, since its maximum occurs over the bar. The model succeeds in capturing both short- and long-wave heights for the low water level case. This validation gives confidence to the model's ability in representing infragravity dynamics for a complex barred-beach case and thus allows for using it in further physical interpretations. 

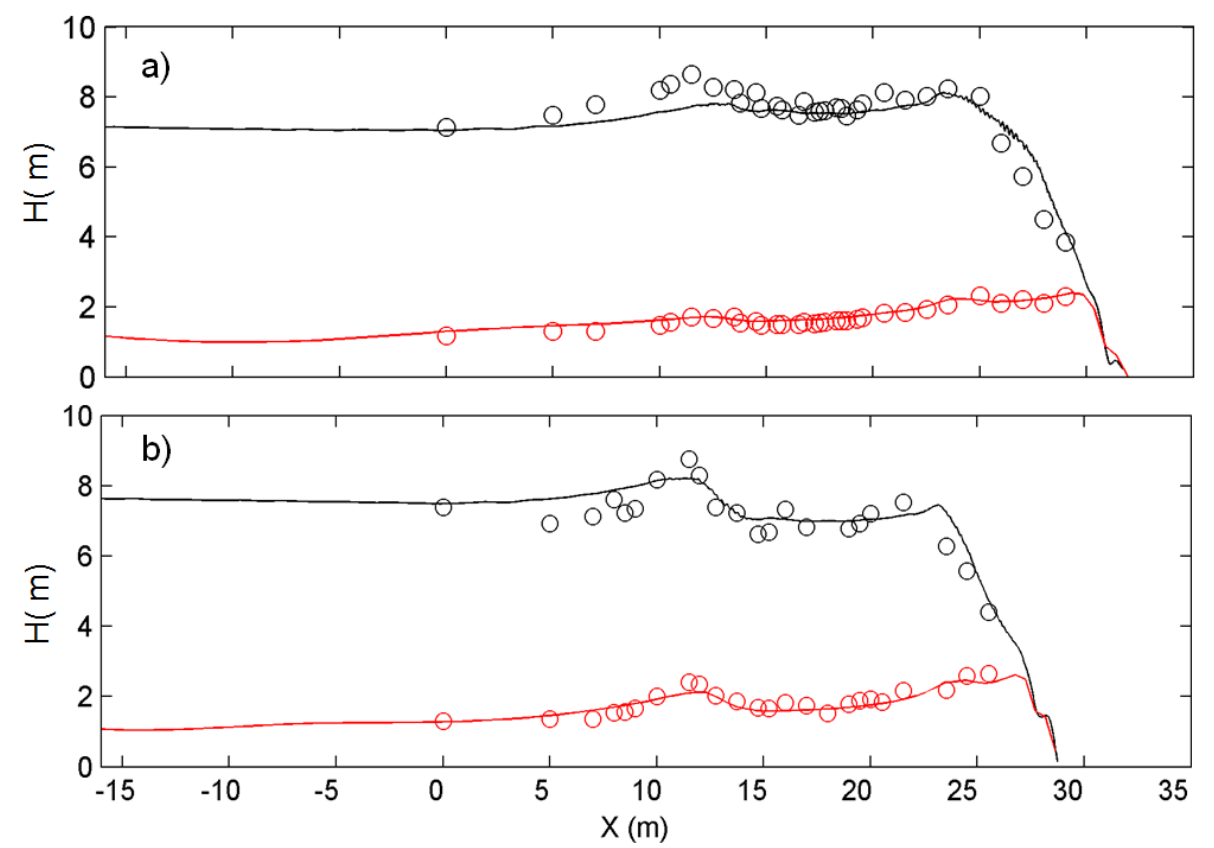

Figure 2: Profiles of high (black) and low-band (red) height for (a) the high and (b) low water levels. Circles are data and lines are model results.

\section{The resonant infragravity pattern}

The total infragravity pattern, as shown in Figure 2, results from the interaction of shoreward and outward propagating long-waves. The Figures 3.a and 3.b show the spatio-temporal pattern for high and low water level cases, respectively. This pattern is complex for the two cases and differences can be seen. The influence of the bar is clearly visible in for the low water case (Figure 3.b), where incident and reflected waves interact positively at the bar location $(x=12 \mathrm{~m})$. Conversely, there is no clear evidence of the bar impact for the high water level case (Figure 3.a). Interestingly, this can be linked with the observed long-wave height peak at the bar location in 2.b which is not substantial in 2.a. To go in further details and to better understand this behavior, the components are isolated through the Radonbased analyze. Resulting incident and reflected components are shown in Figures 3.c, 3.e and 3.d, 3.f, respectively for the high and low water levels. Incident waves are rather similar whereas reflected waves are contrasted. Offshore from the bar location, reflected wave amplitude decreases with distance to the shore, as they do for a monotonous beach. However for the low water level, before the bar, they shoal as they propagate offshore.

These observations show that a change in the water level affects short-waves which later influences long-waves dynamics. The incident and reflected long-wave thus may interact differently: positively or negatively. Identifying the factors that influence the resonance pattern is essential to understand infragravity dynamics. In the following section we explore the role of supposed key beach shape characteristics (bar location, amplitude and upper beach slope) on infragravity resonance. 

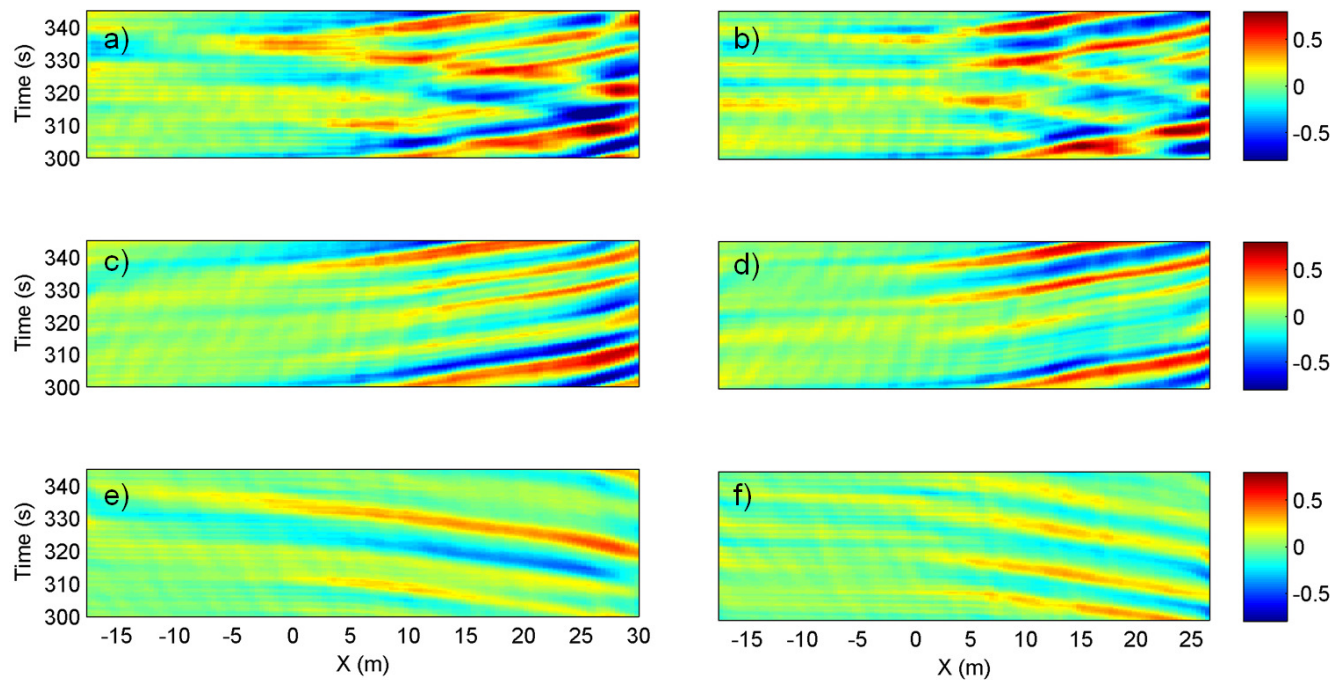

Figure 3: Low-frequency surface elevation (in $\mathrm{cm}$ ) spatio-temporal from resistive rods for (left panels) high water and (right panels) low water levels; respectively the (up) total, incident (mid) and reflected field (low).

\section{Numerical analysis of morphological influence on infragravity dynamics}

The influence of changing bar amplitude, location, and upper beach slope on infragravity resonance is now studied. The resonant condition is characterized by the correlation between incident and reflected components. For the simulations, JONSWAP wave conditions are statistically identical to the ones investigated in the experimental set-up. The bathymetric profile is obtained by superimposing a Gaussian-shape bar with a fixed width and variable amplitude $\left(\mathrm{A}_{\mathrm{b}}\right)$ and location $\left(\mathrm{x}_{\mathrm{b}}\right)$ to a monotonous beach. The upper beach slope $\mathrm{sl}_{\mathrm{swash}}$ is left as a variable.

In Figure 4.a are shown three bathymetric profiles with $A_{b}=0,0.12$ and $0.2 \mathrm{~m}$. The resulting shortwaves and incident and reflected long-waves height are shown in Figure 4.b and 4.d, respectively. It can be seen that short-wave breaking over the bar intensifies with $A_{b}$, together with an increase of long waves height peak over the bar. As a consequence, and as shown in Figure 4.e, with a stronger control of infragravity pattern played by the bar, the correlation between incident and reflected waves is higher when depth over the bar is lower. In other words, the resonance increases with $A_{b}$. In Figure 4.f is represented an estimation of the resonant energy computed from the total infragravity band. Following the increasing resonance, the trapped energy increases with $A_{b}$. Relative change of trapped energy is weak, ranging from 0 to $4 \%$ of the maximum for the $A_{b}=0.2 \mathrm{~m}$ case. But bar not only can vary in amplitude, it may migrate in the cross-shore affecting both short and long-wave dynamics. In the next paragraph we investigate the effect of $\mathrm{x}_{\mathrm{b}}$ in the infragravity resonance. 

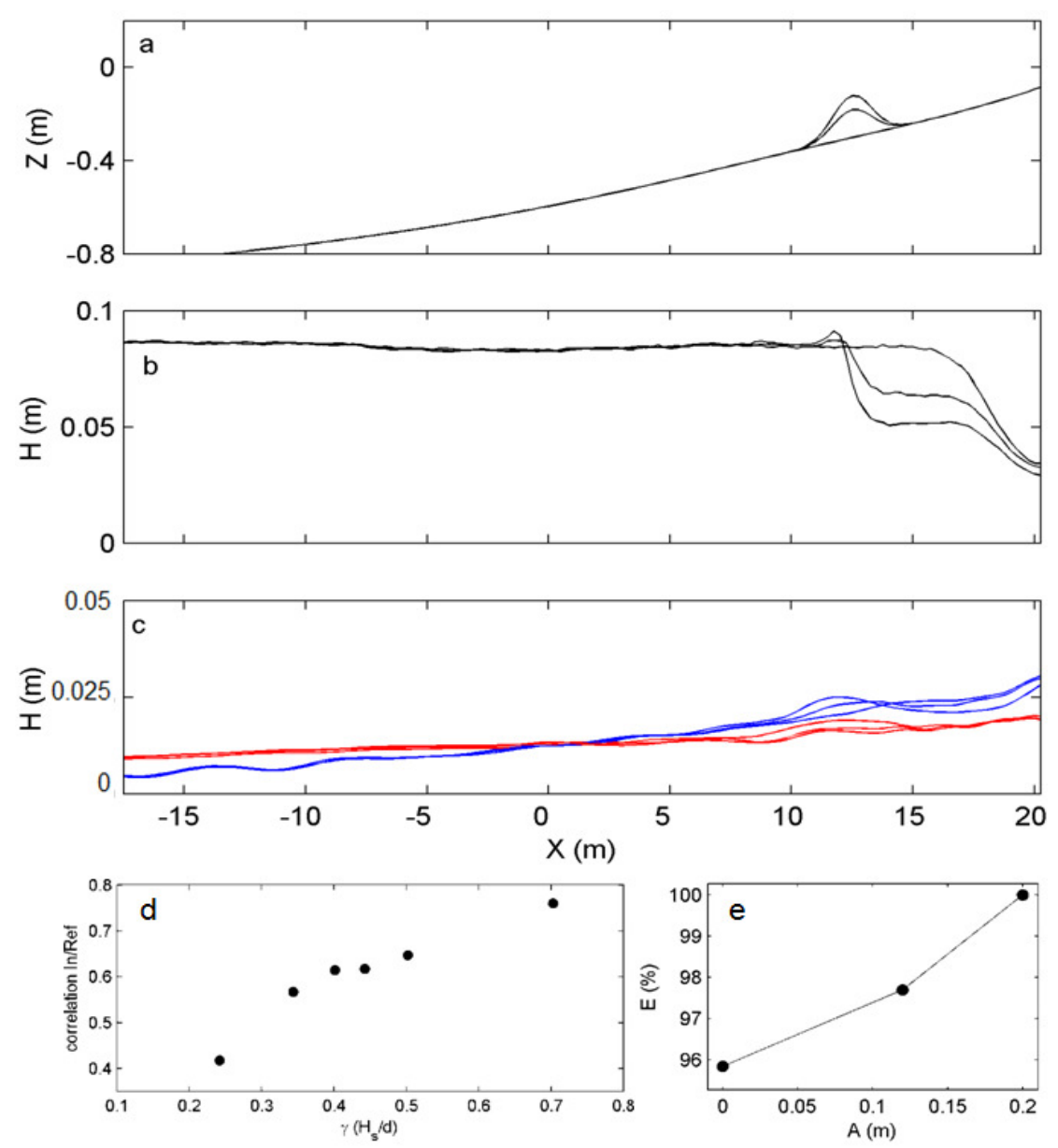

Figure 4: Infragravity resonance sensitivity to bar amplitude. (a) bathymetric profiles, (b) significant wave heights, (c) incident (blue) and reflected (red) infragravity amplitudes and their (d) correlation value for varying amplitude (or wave-height-to-depth ratio), (f) total trapped resonant energy.

In Figure 5.a are shown the bathymetric profiles with bar location varying from $\mathrm{x}_{\mathrm{b}}=7,12$ to $20 \mathrm{~m}$. We choose to keep the depth-over-the-bar constant in order to conserve the short-wave breaking dynamic (intensity, type) over the bar. Resulting short- and both incident and reflected long-waves amplitudes are shown in Figure 5.b and 5.d respectively. It can be seen that short-wave pattern is highly influenced by $\mathrm{x}_{\mathrm{b}}$, since the breakpoint location is modified. Long-wave pattern is also significantly changed. The peak over the bar for the incident component roughly follows the location $\mathrm{x}_{\mathrm{b}}$, but reflected long-wave height profiles appears to be very different. In Figure 5.e we show the correlation between incident and reflected components as a function of the bar location, $\mathrm{x}_{\mathrm{b}}$. Resonance varies from negative to positive, depending on $\mathrm{x}_{\mathrm{b}}$. It worth noting that a negative value means that reflected waves interact with incident ones in a destructive way (decrease amplitude) whereas long-wave amplitude is amplified if resonance is constructive. Interestingly, positive resonance is encountered for the "real" location ( $\mathrm{x}_{\mathrm{b}}=12 \mathrm{~m}$, which scales with the Truc Vert beach profile) of the bar. The resonant trapped energy shown in Figure 5.f follows the same behavior with an energy maximum for a bar located at $x_{b}$ $=12 \mathrm{~m}$, when the resonance is maximum. Relative change of trapped energy is larger than for bar amplitude variation, ranging from 0 to $8 \%$ of the maximum for the bar located at $x_{b}=12 \mathrm{~m}$. We have seen so far that resonance is influenced by various bar parameters, we will study now what is the role of the upper beach profile. 

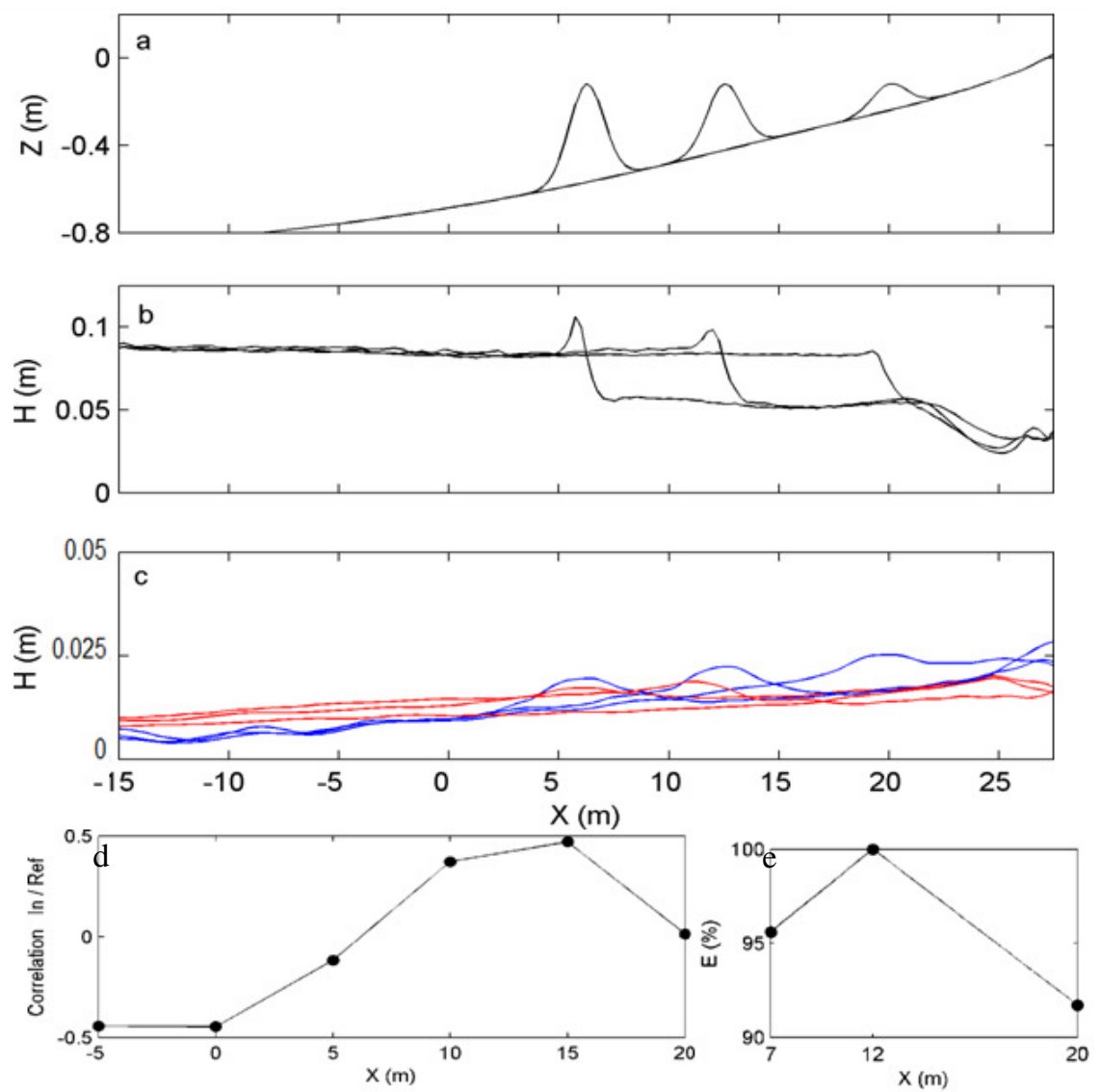

Figure 5: Infragravity resonance sensitivity to bar location. (a) bathymetric profiles, (b) significant wave heights, (c) incident (blue) and reflected (red) infragravity amplitudes and their (d) correlation value over the bar for varying bar location, (e) total trapped resonant energy.

In Figure 6.a are shown monotonous bathymetric profiles with swash zone slope of $\mathrm{sl}_{\mathrm{swash}}=$ $0.01,0.05$ and 0.1 . Resulting short-waves and long-waves (incident and reflected components) amplitudes are shown in Figure 6.b and 6.d respectively. Short-wave pattern is highly controlled by the $\mathrm{sl}_{\text {swash }}$, which influences the breakpoint location, whereas incident long-wave is only weakly affected. On the contrary, reflected long-waves are dramatically affected, having amplitude values that increase with $\mathrm{sl}_{\text {swash. }}$. In Figure 6.e is shown the resonant infragravity pattern for varying $\mathrm{sl}_{\text {swash }}$. The amplitude of the resonant structure increases with $s l_{\text {swash }}$ while node and antinodes migrate offshore. The observed migration of resonant structures may be attributed to a change of $\mathrm{sl}_{\text {swash }}$ which modifies the phase timelag of the reflected component. The decrease in amplitude is directly linked to the larger swash dissipation for flatter slopes and resulting weaker reflection. For instance, considering the very flat $\mathrm{sl}_{\text {swash }}=0.01$ case, only incident wave signature is present from a non substantial reflection. The resonant trapped energy shown in Figure 6.f follows the same tendency with an energy increasing when $\mathrm{sl}_{\mathrm{swash}}$ steepen. Contrary to the relatively small effect of $\mathrm{A}_{\mathrm{b}}$ and $\mathrm{x}_{\mathrm{b}}$, the relative change of trapped energy associated to a change in $\mathrm{sl}_{\text {swash }}$, is large, ranging from 0 to $25 \%$ of maximum $\mathrm{sl}_{\text {swash }}=0.1$ case. 

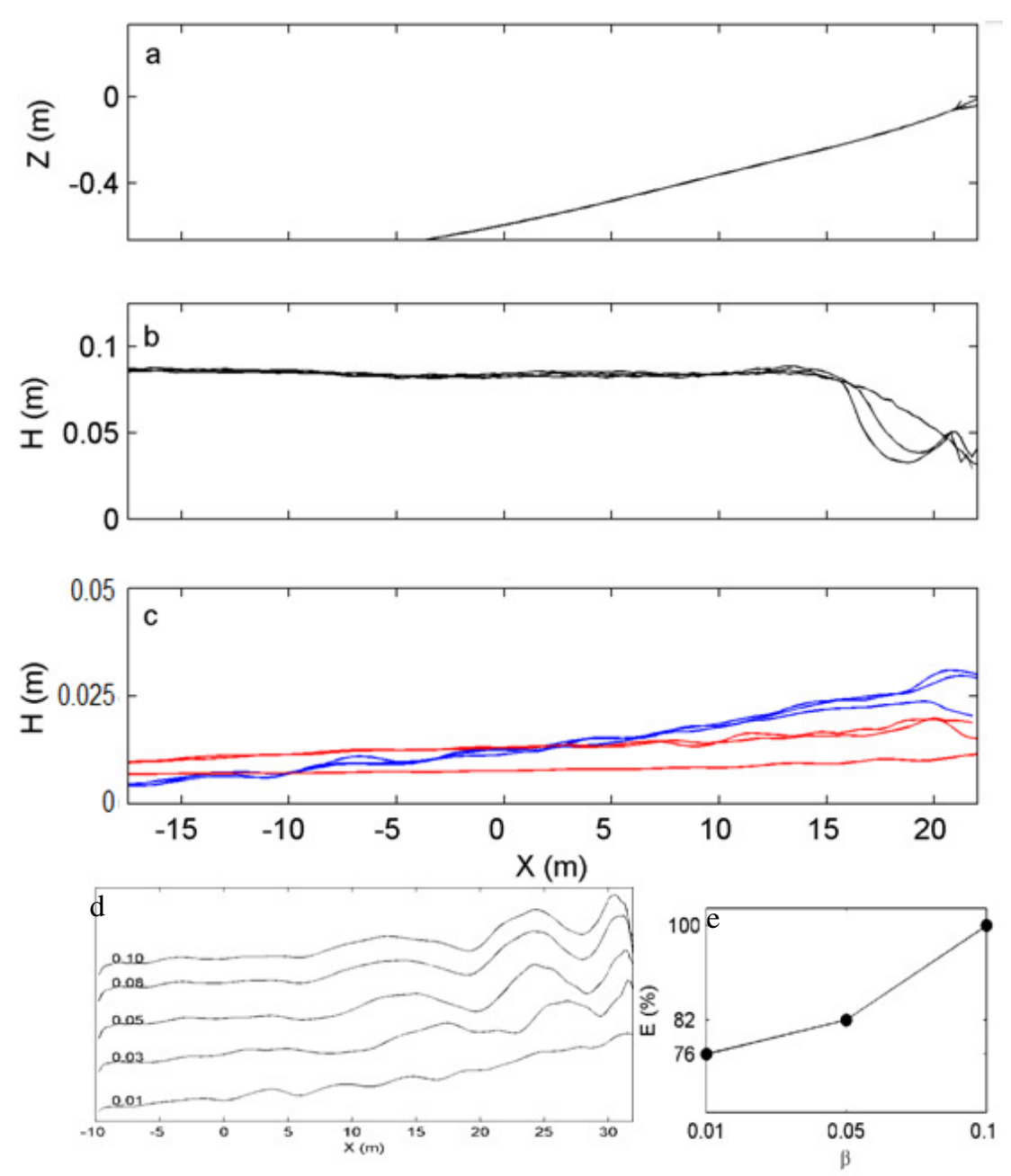

Figure 6: Infragravity resonance sensitivity to swash zone slope. (a) bathymetric profiles, (b) significant wave heights, (c) incident (blue) and reflected (red) infragravity amplitudes. (d) Infragravity resonant pattern for varying swash zone slope and related (e) total trapped resonant energy.

This sensitivity analysis points out that infragravity resonance is strongly influenced by morphology, and in particular, we have seen the key role played by $\mathrm{A}_{\mathrm{b}}, \mathrm{x}_{\mathrm{b}}$ and $\mathrm{sl}_{\text {swash }}$. Now, if a mobile bed is considered, a changing short-wave conditions may affect morphology which later influences infragravity dynamics. Infragravity has a feedback on short-waves dynamics, by modulating short wave characteristics (e.g. breaking) which at the end may influence morphologic evolution. It may thus exist a morphological feedback through infragravity that could accelerate or reduce morphological evolution. For instance, a growing bar under constant short-waves will enhance infragravity resonance which increase short-wave breaking and accelerate bar growth if the bar grows at a positive resonance location. This hypothesis resulting from our analysis should be further verified and quantified through additional studies.

\section{CONCLUSION}

Our combined experimental and numerical investigation of short-waves propagating over a barred beach profile shows the strong influence of morphology on infragravity behavior and resonance. The bar amplitude and location play a key role in infragravity resonance intensity and spatial structure. By using a novel technique for incident and reflected waves separation based on Radon-transform, we show that correlation at the breakpoint intensifies with bar amplitude and varies in sign with bar location. We observed that changing bar characteristics might induce substantial variations in trapped energy in the order of 5-10\%. Interestingly, a modification of swash zone slope has a large influence on reflected long-waves, controlling the amplitude and the phase time-lag, and consequently the resonant pattern. Variations of trapped infragravity energy induced by changes in the upper beach slope reach 25 $\%$. These changes in the infragravity pattern affect short-wave dynamics by modifying the breakpoint 
location and the breaking intensity. The investigation made in this paper suggests the existence of a morphological feedback through the action of evolving morphology on infragravity motions, which modulates the action of short-waves on the morphology itself.

\section{ACKNOWLEDGMENTS}

R.A funded by project FONDECYT Project 3110030 and Observatoire Midi-Pyrénées. R.C acknowledge the funding support from FONDECYT Project 1120878.

\section{REFERENCES}

Aagaard, T., Bryan, K., 2003, Observations of infragravity wave frequency selection. Continental Shelf Research, 23, 10, 1019-1034.

Baldock, T.E. , Holmes , P., 1999. Simulation and prediction of swash oscillations on a steep beach. Coast. Eng. 36, 219-242.

Baldock, T. E., O'Hare, T. J. and Huntley, D. A. 2004. Long wave forcing on a barred beach. J. Fluid Mech. 503, 321-343.

Cienfuegos, R., Barthelemy, E., Bonneton, P., 2010a. A wave-breaking model 34 for Boussinesq-type equations including roller effects in the mass conservation equation. J. Waterw. Port Coastal Oc. Eng. 136, 10-26.

Cienfuegos, R., Duarte, L., Suárez, L. and Catalán. P. 2010b. Numerical Computation of Infragravity Waves and Velocity Profiles using a Fully Nonlinear Boussinesq Model, 32nd International Conference on Coastal Engineering, Shanghai, China, 2010.

Deans, S., 1983. The Radon transform and some of its applications, 1st Edition. Wiley, New York.

Guza, R.T., Thorton, E.B., Holman, R.A. 1984. Swash on steep and shallow beaches. Proceedings of the 19th International Conference on Coastal Engineering, ASCE, 708-723.

Michallet, H., Grasso, F. and Barthélemy, E. 2007. Long waves and beach profiles evolutions. Journal of Coastal Research, SI50, 221-225.

O'Hare, T.J., and Huntley, D.A. 1994. Bar formation due to wave groups and associated long waves, Marine Geology, 116, 313-325.

Ruessink, B.G., 1998. The temporal and spatial variability of infragravity waves in a barred nearshore zone. Continental Shelf Research, 18, 585-605.

Sénéchal, N., Bonneton, P., Dupuis, H. 2002. Field experiment on secondary wave generation on a barred beach and the consequent evolution of energy dissipation on the beach face. Coastal Eng 46, 233-247.

Senechal, N., Abadie, S., Gallagher, E., MacMahan, J.H.M., Masselink, G., Michallet, H., Reniers, Ad J.H.M., Ruessink, B.G., Russell, P.E., Sous, D., Turner, I.L., Ardhuin, F., Bonneton, P., Bujan, S., Capo, S., Certain, R., Pedreros, R. , Garlan, T. 2011. The ECORS-Truc Vert'08 nearshore field experiment: presentation of a three-dimensional morphologic system in a macro-tidal environment during consecutive extreme storm conditions, Ocean Dynamics, DOI: 10.1007/s10236-011-0472-x.

Symonds, G., Huntley, A., Bowen, A., 1982. Two-dimensional surf-beat: long-wave generation by a time-varying breakpoint. J. Geophys. Res. 87, 492-498.

Van Dongeren, A.R., Battjes, J.A., Janssen, T.T., van Noorloos, J., Steenbergen, K., Reniers, A. 2007. Shoaling and shoreline dissipation of low-frequency waves, Journal of Geophysical Research, 112 (C02011).

Wijnberg, K.M., and Kroon., A., 2002. Barred beaches, Geomorphology 48, 103-120. 